\title{
New records of Pluteus (Agaricales) from Paraná State, Brazil
}

\section{Dias RL and Cortez VG}

Universidade Federal do Paraná, Rua Pioneiro 2153, Jardim Dallas, CEP 85950-000, Palotina, PR, Brazil

Dias RL, Cortez VG 2013 - New records of Pluteus (Agaricales) from Paraná State, Brazil. Mycosphere 4(5), 937-943, Doi 10.5943/mycosphere/4/5/6

\begin{abstract}
In a survey of the agarics from the western region of Paraná State, south Brazil, three new records are presented: Pluteus argentinensis is a new record from Brazil, while P. cervinus and $P$. globiger are new records from the State of Paraná. Descriptions and photos of both macro- and microscopic features are given, with a brief discussion on their taxonomy and distribution.
\end{abstract}

Key words - agaricoid fungi - mycobiota - Neotropical - pluteoid clade - taxonomy

\section{Introduction}

Pluteus Fr. is a large and widespread genus in Pluteaceae Kotl. \& Pouzar, comprising ca. 300 species worldwide (Kirk et al. 2008). The pluteoid habit, free and pinkish lamellae with an inverse bilateral trama, stipe without volva and mostly exannulate, smooth and pinkish spores are some diagnostic features of the genus (Orton 1986, Singer 1986). Recent molecular phylogeny studies changed Pluteus taxonomy, with the inclusion of annulate species formerly included in Chamaeota (W.G. Sm.) Earle and re-evaluation of infra-generic classification (Minnis et al. 2006, Justo et al. 2010a,b).

In Brazil, about 70 Pluteus taxa and were reported from several States in the country (Menolli \& Capelari 2008, Putzke \& Wartchow 2008, Menolli et al. 2010). From the State of Paraná, Meijer (2008) reported 34 Pluteus species, including 10 unnamed taxa. During a macrofungal survey in the western region of Paraná State (Ferreira \& Cortez 2012), specimens of Pluteus were collected and some are reported here. This investigation aimed to provide data for the knowledge of the mycobiota from southern Brazil, with particular reference to western region of Paraná State.

\section{Materials \& Methods}

This study was undertaken at the São Camilo State Park (abbreviated onwards as PESC), a conservation unit placed in the municipality of Palotina, western region of the State of Paraná, in Southern Brazil $\left(24^{\circ} 18^{\prime} 00^{\prime \prime}-24^{\circ} 19^{\prime} 30^{\prime \prime} \mathrm{S}\right.$ and 53 $\left.53^{\prime} 30^{\prime \prime}-53^{\circ} 55^{\prime} 30^{\prime \prime} \mathrm{W}\right)$. The area is a fragment of Seasonal Semideciduous Forest, in the Domain of the Atlantic Forest, and comprises an area of ca. 387 ha. (IAP 2006). Specimens were collected from March 2010 and June 2012 and are preserved at the mycological collection of Universidade Federal do Paraná, Campus Palotina (HCP). Macroscopic and microscopic examinations were performed according to Largent (1986) and Largent et al. (1977), respectively. Color names and codes follow Kornerup \& Wanscher (1978). In basidiospores' descriptions, $\mathrm{Q}$ is the range of the length/width quotient for all measured basidiospores, $\mathrm{Qm}$ is the average of all $\mathrm{Q}$ values obtained, and $\mathrm{n}$ indicates the number of measured basidiospores. 


\section{Taxonomy}

Pluteus argentinensis Singer, Lloydia 21: 230, 1959 ('1958')

Figs $1-6$

Basidioma pluteoid, solitary, on woody litter, in the forest. Pileus $43 \mathrm{~mm}$ diam., convex, surface densely fibrillose to slightly squamulose, yellowish brown (5F8) on a grey (6B1) background, margin entire, non-striate; context $2 \mathrm{~mm}$ thick near stipe insertion to $1 \mathrm{~mm}$ near the pileus margin, yellowish white (4A2). Lamellae close, free, distant about $1 \mathrm{~mm}$ each other, <4.5 $\mathrm{mm}$ diam, greyish orange (5B3), margin entire and concolor with sides. Stipe $68 \times 6 \mathrm{~mm}$, central, inserted, subcylindrical, tapering from the base towards the apex, surface fibrillose, beige/greyish yellow (4C3), context fibrous, greyish yellow (4B3). Spore-print reddish grey (7B2).

Basidiospores 5.5-7.6 $\times 5.5-7.1 \mu \mathrm{m}, \mathrm{Q}=0.9-1.2, \mathrm{Qm}=1.0, \mathrm{n}=30$, globose to subglobose, pale greenish to hyaline under $\mathrm{KOH}$, smooth and little thickened walls, guttulate. Basidia $25-36 \times$ 8-9 $\mu \mathrm{m}$, subclavate to subventricose, tetrasporic. Cheilocystidia $42-83 \times 12-22 \mu \mathrm{m}$, mostly ventricose to broadly sublageniform, hyaline, thin-walled. Pleurocystidia 62-91 $\times 11-24 \mu \mathrm{m}$, ventricose, hyaline, thin-walled. Hymenophoral trama divergent, composed of long and cylindrical hyphae, 4-27 $\mu \mathrm{m}$ diam., smooth and thin-walled. Pileipellis formed of filamentous and elongated hyphae, 41.5-93.9 × 8.4-16.4 $\mu \mathrm{m}$, smooth and thin-walled, with a brownish intracellular pigment uniformly dissolved in the hyphae, the terminal elements usually with a attenuate apex, but not capitate or rostrate. Clamp connections absent.

Known distribution - Neotropical: México, Argentina and south Brazil (new record).

Material examined - Brazil, Paraná, Palotina, PESC, 19 Oct 2011, R.L. Dias 27-4 (HCP).

Discussion - This species was described from Argentina, and later reported from Mexico (Rodriguez \& Guzmán-Dávalos 1999). Materials collected at PESC fits very well with original description by Singer (1959), except for the presence of slightly larger pleurocystidia (34-68 $\times 14$ $25 \mu \mathrm{m})$ and a few smaller hyphae of pileipellis $(91-127 \times 16.5-18.7 \mu \mathrm{m})$, but we consider it in the variation of the species. Wright \& Albertó (2002) present a description, photo and line drawings of their material from the region of Buenos Aires, however it is possibly misidentified because $P$. argentinensis is a non-clamped species and their figures show conspicuous clamp-connections in pileipellis hyphae and basidia base. Pluteus argentinensis is a new record from Brazil.

Pluteus cervinus (Schaeff.) P. Kumm., Führ. Pilzk.: 99, 1871

Figs $7-12$

Basidiomata pluteoid, growing in pairs, on wood in decomposition. Pileus $80-110 \mathrm{~mm}$ diam., applanate to shallowly depressed but not umbilicate, yellowish brown (5E5), surface radially silky-fibrillose, dry; context fleshy, up to $6 \mathrm{~mm}$ thickness, brownish orange (5C6). Lamellae close, free, distant about $1 \mathrm{~mm}$ from each other, 6-10 mm, greyish orange (5B3), margin entire and concolor with sides. Stipe 95-105 × 7-9 mm, central, clavate, with basal mycelium, surface fibrillose, white (5A1), context fibrous, white (5A1) and 7-9 $\mathrm{mm}$. Spore-print not seen.

Basidiospores 5-9 $\times 3-6 \mu \mathrm{m}, \mathrm{Q}=1.2-1.8, \mathrm{Qm}=1.5, \mathrm{n}=50$, broadly elliptical to oblong or subglobose, smooth and thick-walled. Basidia 23-35 × 7-10.5 $\mu \mathrm{m}$, ventricose to subclavate, tetrasporic. Cheilocystidia 25-47 $\times 11-17 \mu \mathrm{m}$, broadly clavate, hyaline, smooth and thin-walled. Pleurocystidia metuloidal, 45-95 × 11-23 $\mu \mathrm{m}$, Cervinus-type, fusoid, with apical and occasionally one lateral horns 5-8 $\mu \mathrm{m}$ long, walls thick $1.8-2.9 \mu \mathrm{m}$, pale greenish under $\mathrm{KOH}$, numerous in the sides of lamellae. Hymenophoral trama divergent, composed of filamentous, 2-16.2 $\mu \mathrm{m}$ diam., cylindrical, smooth and thin-walled. Pileipellis formed by prostrate, parallel hyphae, 5.5-7 $\mu \mathrm{m}$, cylindrical, smooth and thin-walled, with a pale brown intracellular pigment. Clamp-connections absent.

Known distribution - known from all continents.

Material examined - Brazil, Paraná, Palotina, PESC, 16 Sep 2011, R.L. Dias 6-1 (HCP).

Discussion - This is the type species of the genus Pluteus and of Sect. Pluteus due to the filamentous pileipellis and presence of metuloidal cystidia (Singer 1986). This latter feature is one of the most important for identification of the species: the cystidia bears apical horns, although in some exceptional cases, they can bear one lateral horn, and are exclusively of Cervinus-type. 

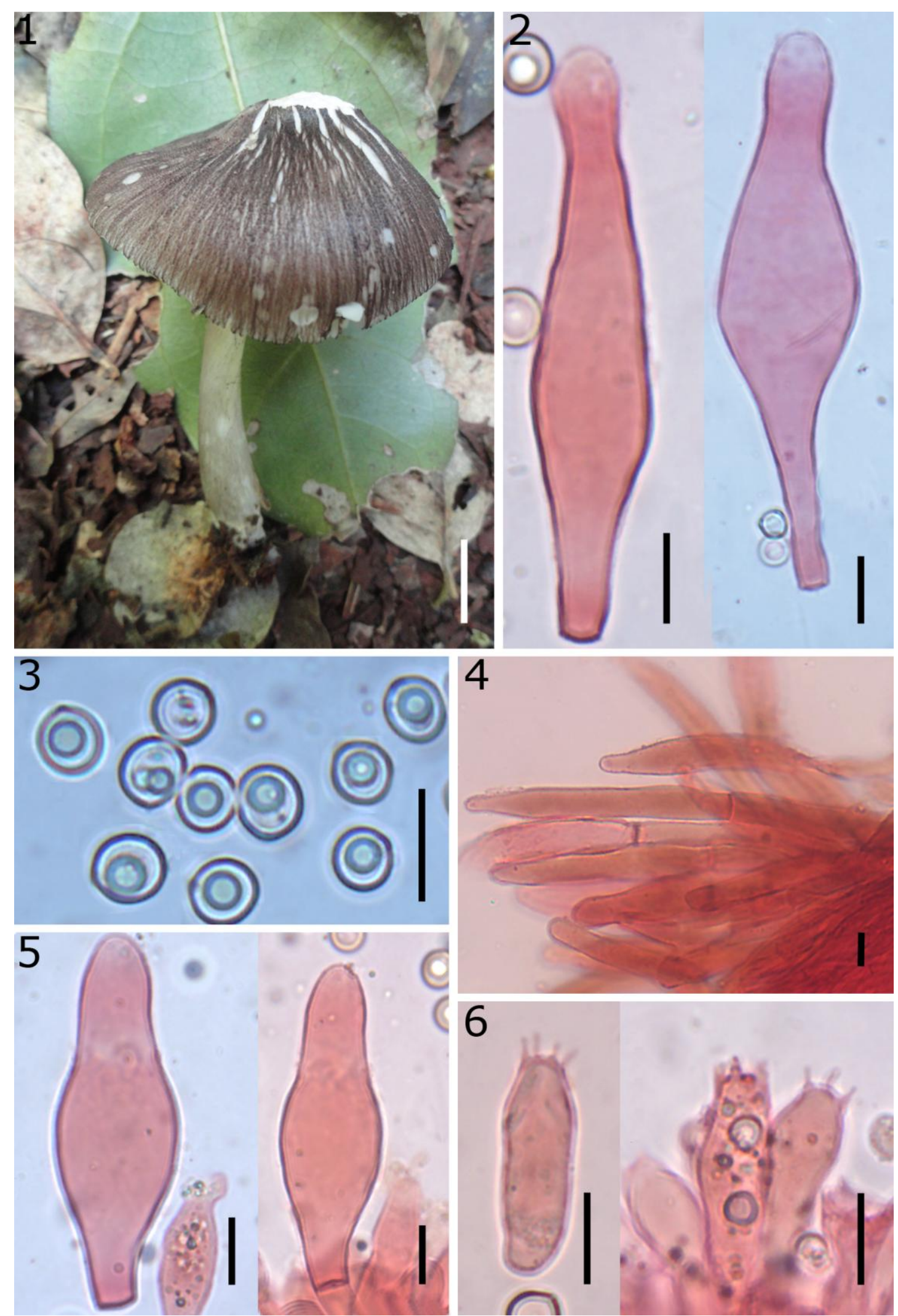

Figs 1-6-Pluteus argentinensis. 1 Basidioma. 2 Pleurocystidia. 3 Basidiospores. 4 Pipelipellis. 5 Cheilocystidia. 6 Basidia. - Bars $=10 \mathrm{~mm}(1), 10 \mu \mathrm{m}(2-6)$. 

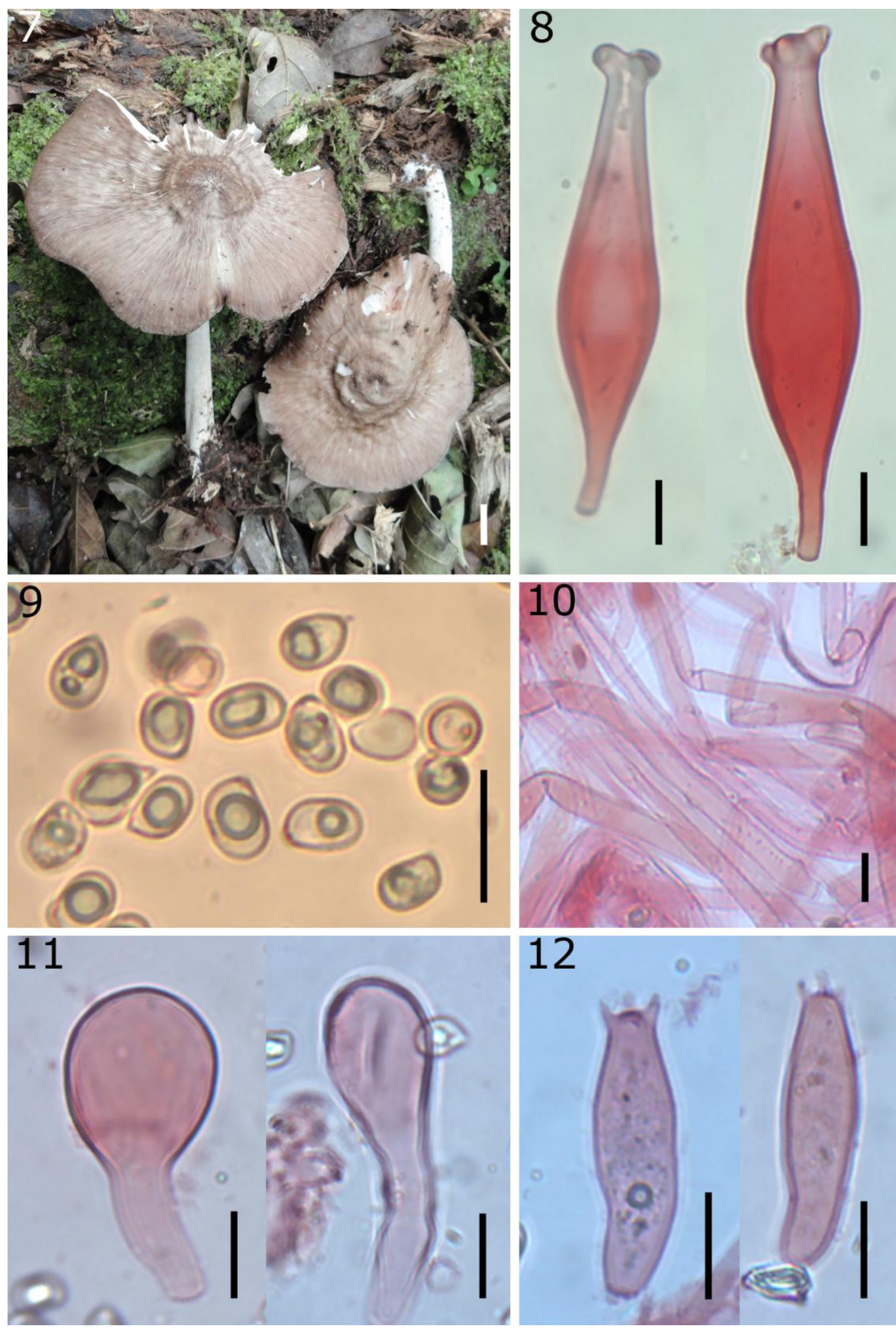

Figs 7-12 - Pluteus cervinus. 7 Basidiomata. 8 Pleurocystidia (metuloids). 9 Basidiospores. 10 Pipelipellis. 11 Cheilocystidia. 12 Basidia. - Bars $=10 \mathrm{~mm}(7), 10 \mu \mathrm{m}(8-12)$. 

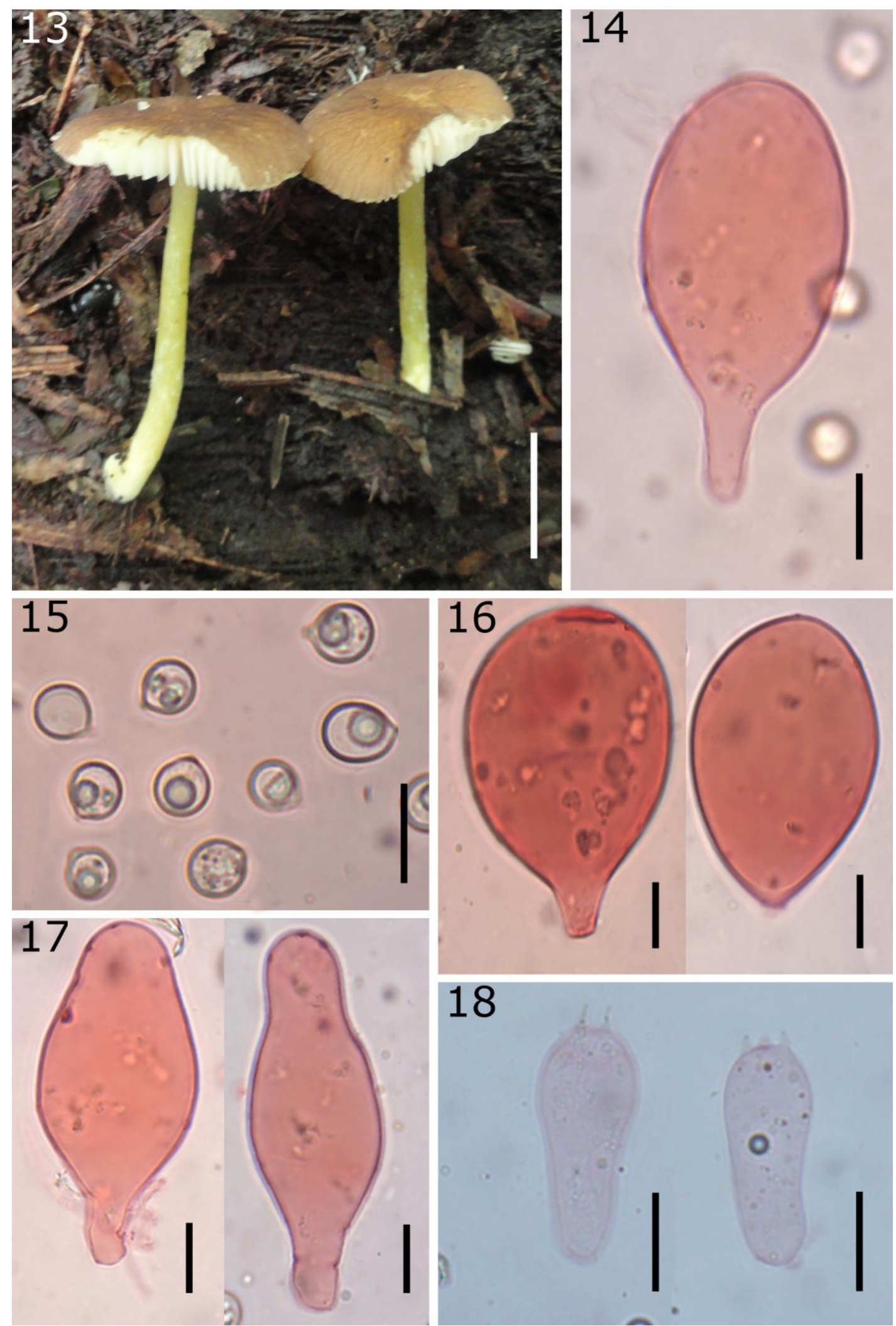

Figs 13-18 - Pluteus globiger. 13 Basidiomata. 14 Cheilocystidia. 15 Basidiospores. 16 Pipelipellis. 17 Pleurocystidia. 18 Basidia. - Bars $=10$ mm (13), $10 \mu \mathrm{m}(14-18)$. 
The absence of clamp-connections is another diagnostic feature in the Sect. Pluteus (Singer 1959). Slightly larger cheilocystidia $(30-60 \times 10-24 \mu \mathrm{m})$ were described by Orton (1986), but the size of south Brazilian specimens agrees with those by Breitenbach \& Kränzlin (1995) for the species. Pluteus xylophilus (Speg.) Singer is the closest species in subtropical Brazil, but differs from $P$. cervinus in the trimorphic pleurocystidia and dimorphic cheilocystidia (Menolli et al. 2010). Pluteus cervinus has been reported from all continents, although little recorded and known from Neotropical region, especially in South America. In Brazil, the only report of the species was from the State of São Paulo (Pegler 1997), since the record of P. cervinus by J. Rick from Rio Grande do Sul correspond to P. xylophilus (Menolli et al. 2010), and thus this is the first record from Paraná.

Pluteus globiger Singer, Lilloa 25: 266, 1952

Figs $13-18$

Basidiomata pluteoid, growing in pairs on decayed wood. Pileus 21-22 mm diam., planoconvex, surface rugulose in the center, to moderately sulcate-striate towards the pileal margin, yellowish brown (5D5), context about $1 \mathrm{~mm}$ in all its extension, pale orange (5A3). Lamellae close, free, distant up to $1 \mathrm{~mm}$ from each other, subventricose, $4 \mathrm{~mm}$ diam., greyish orange (6B3), margin entire and concolor with sides. Stipe 30-37 $\times 2 \mathrm{~mm}$, central, subcylindrical, slightly tapering from the base towards the apex, inserted base, surface delicately fibrillose, dull yellow (3B3) to greyish yellow (3C3), with a cartilaginous appearance, fistulous, context brownish orange (5C5). Spore print brownish orange (6C3).

Basidiospores 5-6 $\times 5-6 \mu \mathrm{m}, \mathrm{Q}=1.0-1.2, \mathrm{Qm}=1.0, \mathrm{n}=25$, globose, guttulate, smooth and thin-walled, hyaline to pale greenish. Basidia 23-30 $\times 7-9 \mu \mathrm{m}$, broadly clavate, bearing four sterigmata 2-2.5 $\mu \mathrm{m}$ long. Cheilocystidia 30-53 $\times 11-27 \mu \mathrm{m}$, ventricose, hyaline to pale yellowish, smooth and thin-walled. Pleurocystidia 25-78 $\times 17-34 \mu \mathrm{m}$, ventricose to broadly lageniform, hyaline, smooth and thin-walled, numerous. Hymenophoral trama divergent, composed of cylindrical and filamentous hyphae, 3.3-14.4 $\mu \mathrm{m}$ diam., with smooth, hyaline and thin walls. Pileipellis cellular, composed of a layer of subglobose or mostly sphaeropedunculate elements, 35$61 \times 27-53 \mu \mathrm{m}$, smooth and thin-walled, with a uniformly dissolved intracellular brown pigment. Clamp connections present.

Known distribution - Neotropical, from México to Argentina and Brazil.

Material examined - Brazil, Paraná, Palotina, PESC, 12 Sep 2011, R.L. Dias 25-1 (HCP).

Discussion - Another species described from Argentina (Singer \& Digilio 1952), characterized by the yellowish color of basidiomata, cellular structure of pileipellis with brownish pigments and globose basidiospores (Singer 1959). The cellular pileipellis indicates its placement in Sect. Celluloderma. Pluteus globiger, with an essentially Neotropical distribution (Rodriguez et al. 1997, Singer 1959), was only reported in Brazil from the State of Rio Grande do Sul (Wartchow et al. 2006) and now it is a new record from the State of Paraná.

\section{Acknowledgements}

We thank the CNPq (Brazil) for financial support to this project (Proc. 478373/2010-4) and student fellowship to RLD, and IAP for allowing fieldwork at PESC (Author. Scient. Res. 212-10).

\section{References}

Breitenbach J, Kränzlin F. 1995 - Fungi from Switzerland. Vol. IV Agarics. $2^{\text {nd }}$ part. Lucerne, Mykologia Lucerne.

Ferreira AJ, Cortez VG. 2012 - Lepiotoid Agaricaceae (Basidiomycota) from São Camilo State Park, Paraná State, Brazil. Mycosphere 3, 962-976.

IAP - Instituto Ambiental do Paraná. 2006 - Plano de Manejo do Parque Estadual de São Camilo. http://www.uc.pr.gov.br/modules/conteudo/conteudo.php?conteudo=25 
Justo A, Vizzini A, Minnis AM, Menolli Jr. N, Capelari M, Rodríguez O, Malysheva E, Contu M, Ghignone S, Hibbett DS. 2010a - Phylogeny of the Pluteaceae (Agaricales, Basidiomycota): Taxonomy and character evolution. Fungal Biology 115, 1-20.

Justo A, Minnis AM, Ghignone S, Menolli Jr. N, Capelari M, Rodríguez O, Malysheva E, Contu M, Vizzini A. 2010b - Species recognition in Pluteus and Volvopluteus (Pluteaceae, Agaricales): morphology, geography and phylogeny. Mycological Progress 10, 453-479

Kirk PM, Cannon PF, Winter DW, Stalpers JA. 2008 - Dictionary of the Fungi. $10^{\text {th }}$ ed. Wallingford, CABI.

Kornerup A, Wanscher JH. 1978 - Methuen Handbook of Colour. $3^{\text {rd }}$ ed. London, Eyre Methuen.

Largent DL, Johnson D, Watling R. 1977 - How to identify mushrooms to genus III: microscopic features. Eureka, Mad River.

Largent DL. 1986 - How to identify mushrooms to genus I: macroscopic features. $3^{\text {rd }}$ ed. Eureka, Mad River.

Meijer AAR. 2008 - Notable Macrofungi from Brazil's Paraná Pine Forests. Colombo, EMBRAPA.

Menolli N, Capelari M. 2008 - Notes on Pluteus (Pluteaceae, Agaricales) from Brazil including two new species and a new record. Mycologia 102, 697-707.

Menolli N, Asai T, Capelari M. 2010 - Records and new species of Pluteus from Brazil based on morphological and molecular data, Mycology 1, 130-153.

Minnis AM, Sundberg WJ, Methven AS, Sipes SD, Nickrent DL. 2006 - Annulate Pluteus species: a study of the genus Chamaeota in the United States. Mycotaxon 96, 31-39.

Orton PD. 1986 - British Fungus Flora. Agarics and Boleti. 4: Pluteaceae: Pluteus and Volvariella. Edinburgh, Royal Botanic Garden.

Pegler DN. 1997 - The agarics of São Paulo, Brazil. London, HMSO.

Putzke J, Wartchow F. 2008 - Lista de espécies de Pluteaceae (Agaricales) que ocorrem no Brasil. Biociências 16, 110-113.

Rodríguez O, Guzmán-Dávalos L. 1997 - New reports of the genus Pluteus (Agaricales) from Mexico. Mycotaxon 61, 473-480.

Rodríguez O, Guzmán-Dávalos L. 1999 - Nuevos registros del género Pluteus (Pluteaceae) en México. Documents Mycologiques 114, 67-78.

Singer R. \& Digilio APL. 1952 - Pródromo de la Flora Agaricina Argentina. Lilloa 25, 5-461.

Singer R. 1959 ('1958) - Monographs of South American Basidiomycetes, especially those from the east slope of the Andes and Brazil. 1. The genus Pluteus in South America. Lloydia 21, 195-299.

Singer R. 1986 - The Agaricales in Modern Taxonomy. $4^{\text {th }}$ ed. Königstein, Koeltz.

Wartchow F, Cortez VG, Coelho G. 2006 - New records of Pluteus (Pluteaceae, Agaricales) from Brazil. Mycotaxon 96, 241-252.

Wright JE, Albertó E. 2002 - Guía de Los Hongos de La Región Pampeana. I. Hongos con Laminillas. Buenos Aires, L.O.L.A. 